\title{
Peroral endoscopic myotomy: techniques and outcomes
}

\author{
Roman V. Petrov ${ }^{1}$, Romulo A. Fajardo ${ }^{2}$, Charles T. Bakhos ${ }^{1}$, Abbas E. Abbas ${ }^{1}$ \\ ${ }^{1}$ Department of Thoracic Medicine and Surgery, Lewis Katz School of Medicine at Temple University, Philadelphia, PA, USA; ${ }^{2}$ Department of \\ General Surgery, Temple University Hospital. Philadelphia, PA, USA \\ Contributions: (I) Conception and design: RA Fajardo, RV Petrov; (II) Administrative support: None; (III) Provision of study materials or patients: \\ None; (IV) Collection and assembly of data: RA Fajardo, RV Petrov; (V) Data analysis and interpretation: All authors; (VI) Manuscript writing: All \\ authors; (VII) Final approval of manuscript: All authors. \\ Correspondence to: Roman Petrov, MD, PhD, FACS. Assistant Professor, Department of Thoracic Medicine and Surgery. Lewis Katz School of \\ Medicine at Temple University, 3401 N Broad St. C-501, Philadelphia, PA, USA. Email: roman.petrov@tuhs.temple.edu.
}

\begin{abstract}
Achalasia is progressive neurodegenerative disorder of the esophagus, resulting in uncoordinated esophageal motility and failure of lower esophageal sphincter relaxation, leading to impaired swallowing. Surgical myotomy of the lower esophageal sphincter, either open or minimally invasive, has been a standard of care for the past several decades. Recently, new procedure-peroral endoscopic myotomy (POEM) has been introduced into clinical practice. This procedure accomplishes the same objective of controlled myotomy only via endoscopic approach. In the current chapter authors review the present state, clinical applications, outcomes and future directions of the POEM procedure.
\end{abstract}

Keywords: Peroral endoscopic myotomy (POEM); minimally invasive esophageal surgery; gastric peroral endoscopic myotomy; achalasia; esophageal dysmotility

Received: 17 November 2019; Accepted: 17 January 2020; Published: 10 April 2021.

doi: $10.21037 /$ shc. 2020.02 .02

View this article at: http://dx.doi.org/10.21037/shc.2020.02.02

\section{Introduction}

Esophageal achalasia is a motility disorder characterized by incomplete or absent lower esophageal sphincter (LES) relaxation and uncoordinated or absent esophageal peristalsis resulting in dysphagia, regurgitation, retrosternal pain, and weight loss. This results from the progressive degeneration of ganglion cells in the myenteric plexus of the esophageal wall. Current therapeutic options including pharmacologic therapy, endoscopic treatment, and surgery all aim to palliate symptoms by decreasing the LES pressure to improve the passage of food bolus across the gastroesophageal junction (GEJ). A minimally invasive Heller myotomy is the most commonly performed surgical procedure for this disorder and is the current standard of care.

In 2008, Inoue et al. has applied a concept of natural orifice transluminal endoscopic surgery (NOTES) for the treatment of esophageal achalasia. The authors published their first experience of this novel endoscopic approach for achalasia in 2010 introducing the term POEM- peroral endoscopic myotomy (1). Following this report, POEM has being rapidly accepted, becoming the primary form of treatment of achalasia at many centers worldwide. Swanstrom et al. popularized this procedure in the United States in 2012 after publishing results of 18 patients with esophageal achalasia (2).

POEM utilizes the principles of myotomy of the distal esophagus and gastric cardia via endoscopic submucosal tunnel, avoiding any skin incisions in the chest or abdomen. This chapter will focus on the endoscopic technique and outcomes of the peroral endoscopic myotomy.

\section{Indications/contraindications}

Symptomatic patients with manometrically proven primary idiopathic achalasia are candidates for POEM. This is the acceptable alternative treatment for type I and II achalasia and the preferred treatment for type III achalasia (3-6). Relative contraindications to POEM procedure are severe 

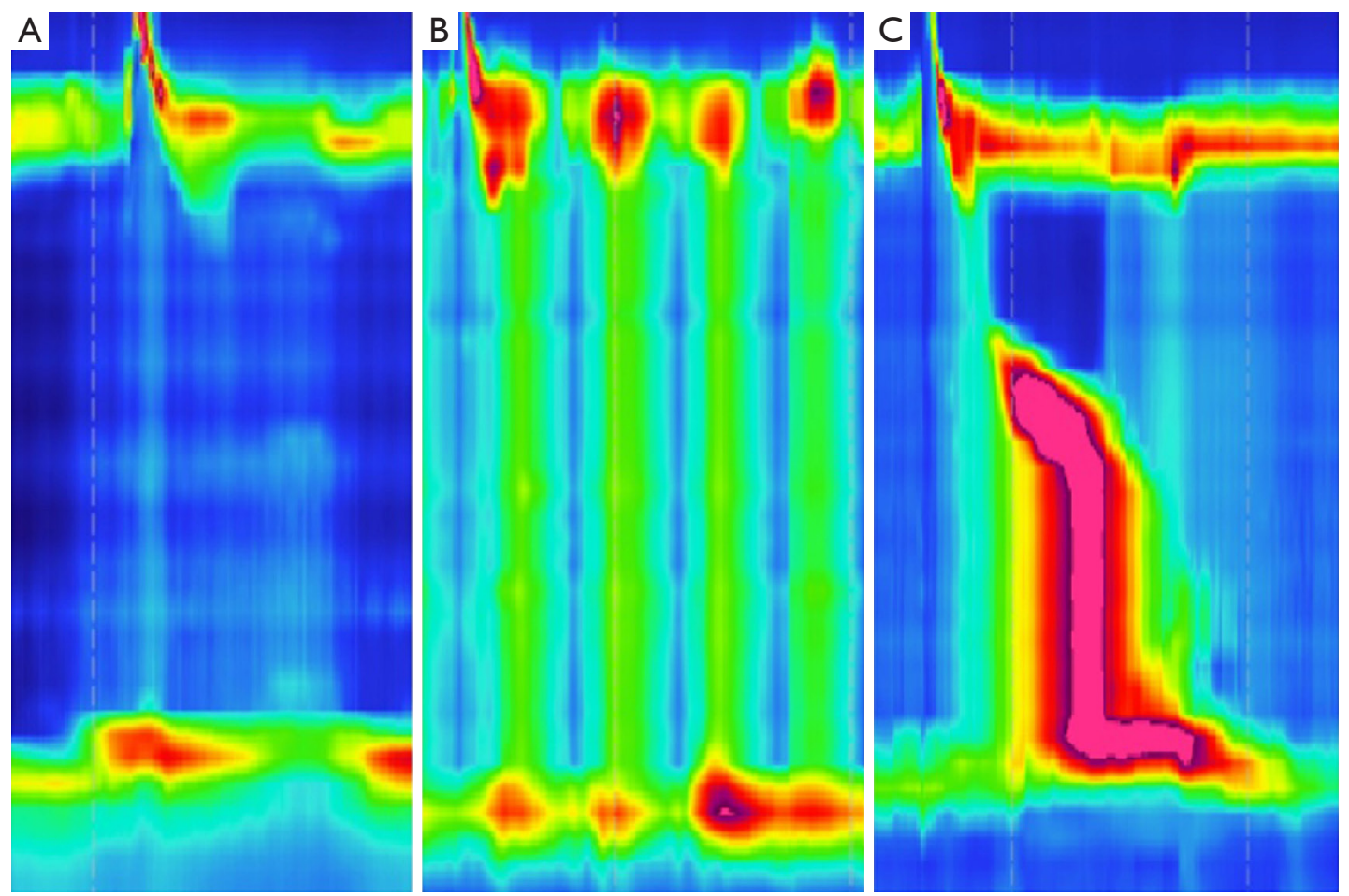

Figure 1 High resolution manometry findings of the different types of achalasia. (A) Type I achalasia. (B) Type II achalasia. (C) Type III achalasia. (Curtesy of Dr. Herit Vachhani, MD).

erosive esophagitis, significant coagulation disorders, liver cirrhosis with portal hypertension and varices, or prior therapy (radiation, endoscopic mucosal resection or radiofrequency ablation). Previous intervention such as pneumatic balloon dilation, pharmacologic injection or surgical myotomy are not considered contraindications to POEM (7-10).

\section{Preoperative evaluation}

A standardized and validated symptom assessment such as the Eckardt score is useful in evaluation of patients. High resolution esophageal manometry testing should be used for the fine assessment of the esophageal motility, subtypes of the achalasia or characterization of other types of spastic esophageal disorders (Figure 1). The clinical significance of this sub-classification is a subject of debate. A contrast esophagram showing the classic "birds beak" appearance of the narrowed esophagogastric junction and esophageal aperistalsis should be evident (Figure 2A). Patients with spastic achalasia might have a "cork screw" appearance on the esophagogram (Figure 2B). In patients with late or endstage achalasia, the esophagus may appear significantly dilated, angulated and tortuous alluding to a sigmoidal shape (megaesophagus) (Figure 2C). Megaesophagus has traditionally being approached surgically although it is not an absolute contraindication for POEM, however alternative therapies may be considered due to the increased technical difficulty (11-14). Identification of large amounts of residual food at the initial endoscopy would lead to aborting of POEM procedure to avoid mediastinal contamination (Figure 3).

\section{Operative technique}

The standard POEM technique consists of four sequential steps: 1: mucosotomy (initial mucosal entry), 2: submucosal tunneling, 3: myotomy proper, and 4: closure of the mucosal defect (Figure 4) $(13,15,16)$. The mucosal site entry is usually performed $10-15 \mathrm{~cm}$ proximal to the GEJ. After creating a submucosal cushion with saline and blue dye mixture, a $2 \mathrm{~cm}$ mucosal incision is created for entry into the submucosal plane (Figure 4A). Subsequently, alternating saline injection with energy dissection, a submucosal tunnel is created. Deposition of colored saline in the submucosal plane enhances demarcation and expands the working space 

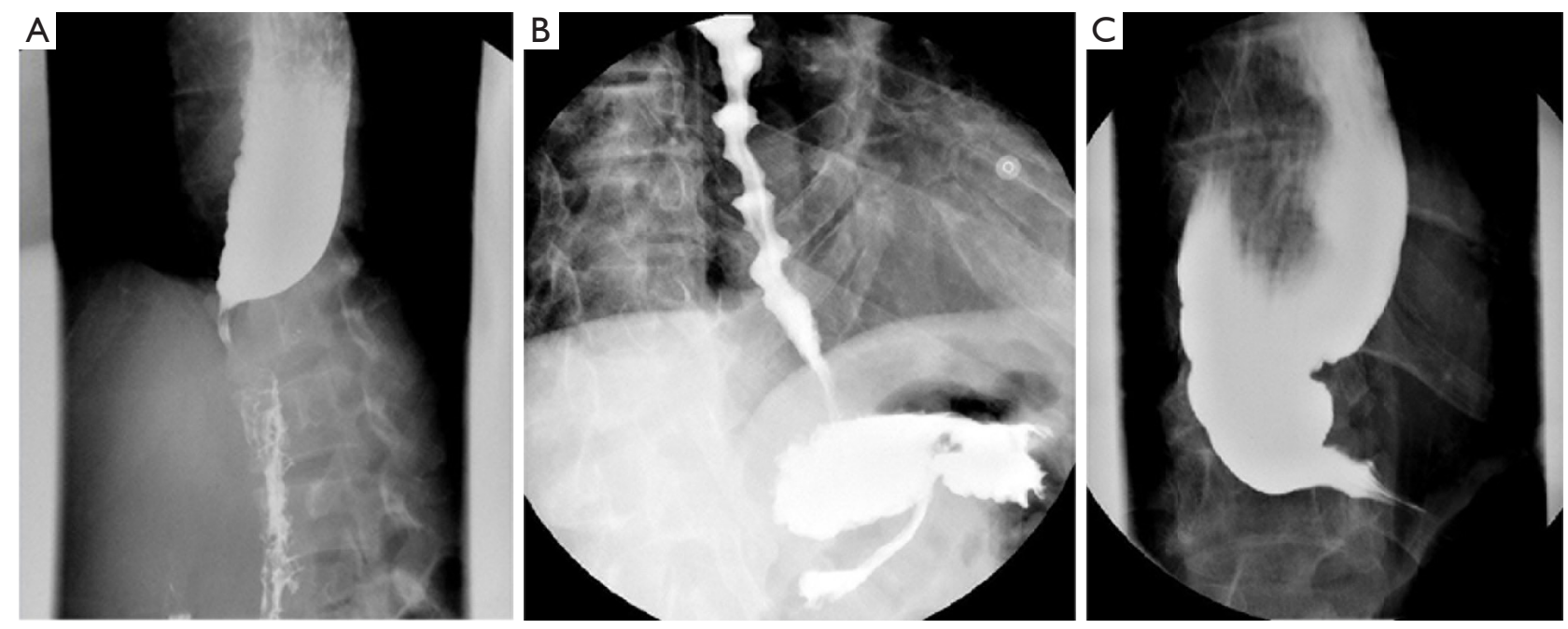

Figure 2 Esophagram appearance of the different types of achalasia. (A) "Birds beak" appearance of the classical achalasia. (B) "Cork-screw" appearance of the spastic achalasia. (C) Sigmoid or end stage achalasia.

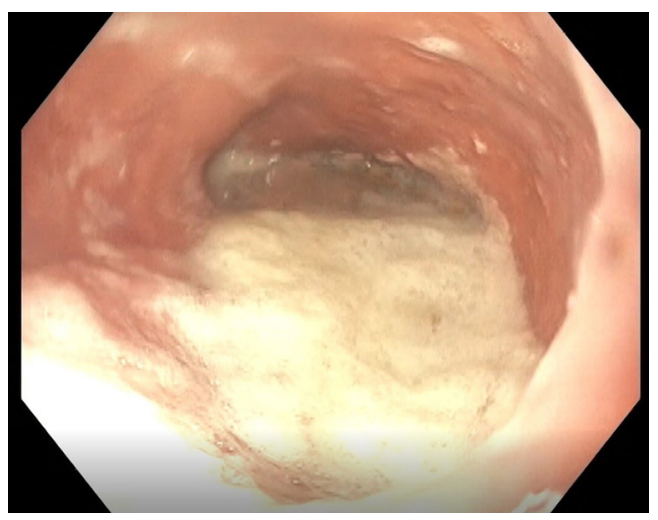

Figure 3 Retained fermented food, fluid and saliva in the end stage achalasia esophagus.

between the muscularis propria and the mucosa. Larger submucosal blood vessels can be individually coagulated for prevention of bleeding. The submucosal tunnel is extended approximately $3 \mathrm{~cm}$ distal to the GEJ to ensure complete disruption of the LES (Figure 4B). Once the submucosal tunnel has been completed, the myotomy is performed, starting 3 to $5 \mathrm{~cm}$ distally to the site of the mucosotomy (Figure $4 C$ ). The optimal depth of the myotomy is not known. Conceivably, preservation of the outer longitudinal muscular layer can prevent dissection plane from entering the mediastinal planes. In a retrospective analysis full-thickness myotomy was associated with significantly shorter procedure times without compromising safety of the procedure (17).
After the myotomy is complete, a careful inspection of the mucosa is performed to detect inadvertent mucosal defects. Endoscopic hemostatic clip closure or an endoluminal suturing device is used to seal the site of mucosal entry (Figure 4D) (13).

There has been an ongoing debate as to the location of the mucosal incision, submucosal tunnel, and myotomy. Initially introduced as an anterior approach for potential surgical correction of the possible complications, POEM is currently more frequently performed via a posterior approach $(18,19)$. In a randomized controlled trial comparing the two approaches Tan et al. did not detect any difference in short-term treatment efficacy, manometry outcomes, and adverse events (20).

POEM provides a unique advantage of individually adapting the extent and location of the myotomy based on the patients' specific characteristics and the type of the achalasia (13). In analysis of impact of high-resolution esophageal manometry (HREM) findings on the myotomy length Kane et al., demonstrated significantly improved postoperative Eckardt scores in the group with tailored (extended) myotomy length in patients with subtype III achalasia (5).

\section{Postoperative care}

There is no standardized postoperative protocol for patients undergoing POEM procedure. Generally, patients admitted to the hospital for overnight observation, kept nil per os (NPO) and given adequate antiemetics and GI 
A

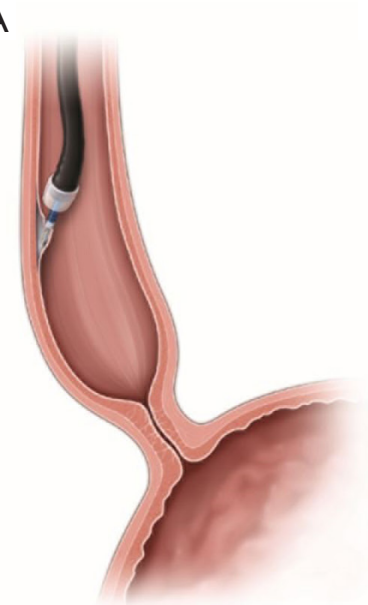

B

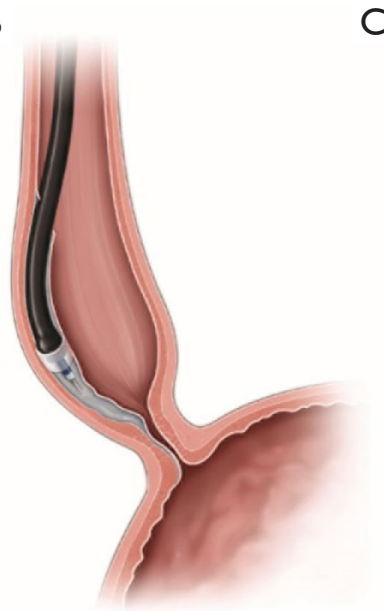

C

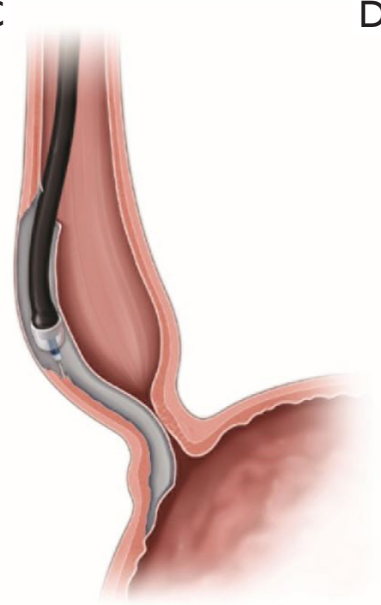

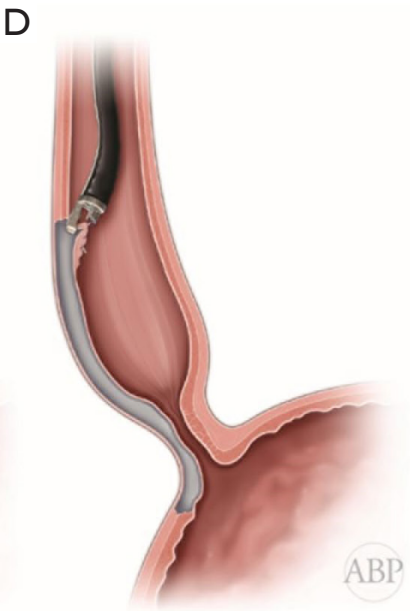

Figure 4 Steps of the POEM procedure. (A) Mucosotomy. (B) Submucosal tunnel. (C) Myotomy. (D) Closure of the mucosotomy.

prophylactics. An esophagram is obtained on the next postoperative day to exclude an esophageal leak. In case of normal study diet is advanced as tolerated over the next few days and patients are discharged home on postoperative day one. Patients can continue their antireflux medications postoperatively and be followed up as an outpatient in a timely fashion $(8,10,21)$.

\section{Outcomes}

Since its first report in 2010, the POEM procedure has quickly become the primary and preferred treatment for esophageal achalasia in numerous centers with thousands of procedures performed world-wide. Despite its wide adoption, the efficacy, safety and feasibility of the POEM procedure is still debated. In an international multicenter study $82 \%$ of 70 patients at 12 months were in remission with esophagitis present in $42 \%$ of patients after POEM (22). In 94 patients after POEM at a mean follow-up of 11 months, excellent results, defined as clinical success, were observed in $94.5 \%$ with postoperative $\mathrm{pH}$ monitoring displaying pathologic reflux in $53.4 \%$ of patients (23). In another analysis of outcomes of 80 patients with achalasia at a mean follow-up of 29 months authors revealed a success rate of $77.5 \%$ with esophagitis present in $37.5 \%$ of patients (24).

Safety of the procedure was demonstrated in the large retrospective multicenter analysis of almost two thousand patients from 12 international centers (13). The study established low overall prevalence of any adverse events, such as inadvertent mucosotomy, esophageal leak, complications related to insufflation, submucosal hematoma, and cardiopulmonary complications at $7.5 \%$ (156 events in 137 patients). Majority of the adverse events were mild to moderate with severe ones present in only $0.5 \%$ cases. The most common adverse event was an inadvertent mucosotomy, occurring in $51(2.8 \%)$ patients. Sigmoid-type esophagus, triangular tip knife, an inexperienced operator ( $<20$ cases performed) and non-spray coagulation were predictive factors of occurrences of adverse events (5).

There is a wide range of complication rates reported in the POEM literature varying from 0 to $72 \%$, likely related to the lack of consensus on terminology. For example, whereas some authors report asymptomatic gas-related events, such as subcutaneous emphysema, pneumoperitoneum, pneumothorax, or mediastinal emphysema as an incidental findings, others give them a grading of a full adverse event $(8,13)$.

The POEM has been favorably compared to other wellestablished treatment modalities for achalasia $(7,10,25)$. Such, in a retrospective analysis comparing 71 patients undergoing POEM versus pneumatic dilation for newly diagnosed achalasia, POEM demonstrated durable effects, while the success rates of pneumatic dilatation progressively declined starting 6 months post-dilatation. The difference was demonstrated in all 3 subtypes of achalasia, but was only statistically significant in patients with type III achalasia (26). In the multicenter comparative study of 75 patients with type III achalasia POEM outperformed laparoscopic Heller myotomy-clinical response rate was superior-98\% vs. $80 \%$ with shorter procedure time (102 vs. $264 \mathrm{~min})$ despite longer myotomy $(16 v s .8 \mathrm{~cm})$ and significantly lower rate of adverse events (6\% vs. 27\%) (27). 
Heller myotomy has been long established as a gold standard therapy for achalasia. Although a surgical Heller myotomy has high rates of symptomatic success and relatively low complication rates, recurrent or persistent symptoms can occur in approximately $10-20 \%$ of patients $(8,28)$. Redo Heller myotomy is a complex and technically challenging procedure. POEM has been demonstrated as a successful rescue endoscopic intervention for patients with failed previous Heller myotomy $(8,21)$. In a retrospective cohort study of 180 patients with achalasia who underwent procedure at thirteen tertiary care centers as a primary procedure or after failed prior Heller myotomy, analysis showed efficacy rates of $98 \%$ in the previous Heller myotomy group and $100 \%$ in the non-Heller myotomy group. The primary outcome of decreasing Eckard score to below 3, was achieved in $81 \%$ of the Heller myotomy group and $94 \%$ in the non-Heller myotomy group, which was statistically significant (8). There was no significant difference in rates of adverse events, symptomatic reflux, and reflux esophagitis. In another report of 8 patients with recurrent dysphagia after failed Heller myotomy, 3 patients underwent redo laparoscopic Heller myotomy with fundoplication and 5 patients underwent redo myotomy with POEM. All patients achieved significant improvement in symptoms and Eckardt scores at an average follow-up of 5 months (9). In a systematic review 36 of 289 patients were treated with POEM after a previous failed Heller myotomy (28). Analysis revealed a technical success rate of greater than $98 \%$ and a rate of insignificant adverse events of $39 \%$. POEM appears to be a safe and effective treatment modality for patients requiring an intervention after failed previous Heller myotomy due to the ability of performing the myotomy in any location of the esophageal lumen, thus avoiding the previous plane of dissection-an advantage not usually available in a redo laparoscopic approach. Moreover, it has been established as a safe redo intervention for failed prior POEM procedure as well. Such, Tyberg et al. reported results of POEM after a failed previous POEM in 46 patients (21). $100 \%$ of patients had technical success and $85 \%$ had resolution of the dysphagia.

Similarly to the Heller myotomy, there is an incidence of post-operative reflux after POEM due to mechanical disruption of the barrier function of the lower esophageal sphincter. Schlottmann et al. compared the efficacy of POEM to the laparoscopic Heller myotomy (LHM) for achalasia in a systematic review and meta-analysis (25). Results showed slight advantage of the POEM over LHM in relieving dysphagia. However, POEM had significantly higher rate of pathologic reflux (OR 1.69), erosive esophagitis (OR 9.31), and abnormal $\mathrm{pH}$ monitoring values (OR 4.30) over surgical myotomy with Dor fundoplication. Kumbhari et al. in a retrospective case-control study reported the prevalence of reflux after POEM in 282 patients. At median follow up of 12 months, a DeMeester score of greater than or equal to 14.72 was seen in $57.8 \%$ of patients with reflux esophagitis present in $23 \%$ of patients upon upper endoscopy. Despite these findings, $60.1 \%$ of patients remained asymptomatic (29).

With an increased incidence of Barrett's esophagus and esophageal adenocarcinoma in patients with long-standing GERD, post-POEM esophageal reflux remains a significant concern (30-34). The use of proton pump inhibitors (PPI) post-POEM has been utilized for the symptomatic control with high success rates and the need for additional fundoplication is very low (35). Recently Tyberg et al. reported on the results of application of incisionless fundoplication (TIF) in the management of the postPOEM reflux (21). In multiple randomized control trials, TIF has been proven superior to high-dose medical therapy for the control of reflux symptoms in GERD patients $(36,37)$. Tyberg et al. demonstrated a $100 \%$ success rate with the discontinuation of PPI use and resolution of esophagitis with a mean follow-up time of 27 months (21). Brewer Gutierrez et al. recently reported on the TIF procedure performed simultaneously with POEM in the same settings (38).

In 2019, Inoue et al. published their yet another innovative procedure of combined endoscopic fundoplication with the standard POEM procedure (POEM + F) (Figure 5) (39). The fundoplication part of the POEM $+\mathrm{F}$ procedure is completed in three steps: entry into the peritoneal cavity (Figure 5A), distal and proximal anchoring of the endoloop with clips (Figure 5B), and closure of the endoloop (Figure 5C). With traction, the gastric fundus would be rotated anteriorly creating a wrap comparable to a surgical Dor partial fundoplication. Authors successfully completed the fundoplication in all 21 of their cases with no immediate or delayed complications. Although as technical paper report did not contain data on the reflux control, POEM + F procedure appears a promising minimally invasive endoscopic alternative to the surgical Heller myotomy and partial fundoplication and potentially can help reduce the incidence of post-POEM gastroesophageal reflux.

\section{Other applications}

Although originally developed for achalasia, the POEM 
A

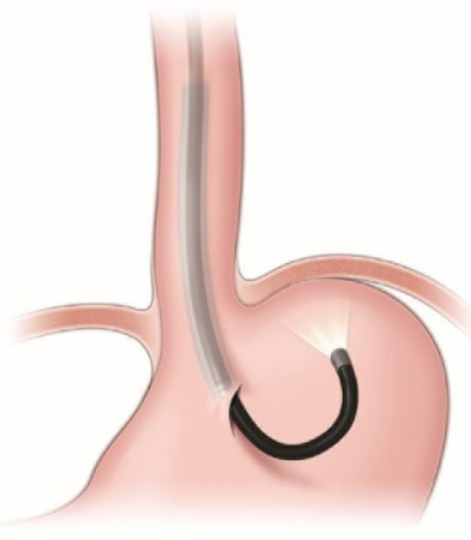

B

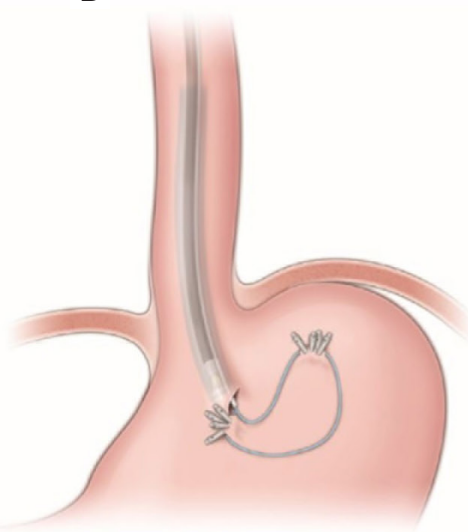

C

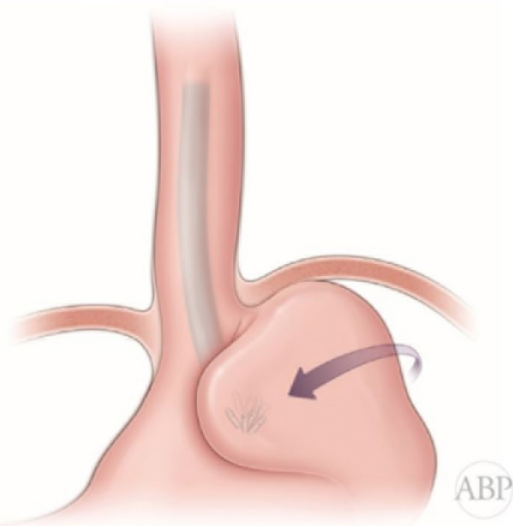

Figure 5 POEM + F procedure steps. (A) Peritoneal cavity entry. (B) Distal and proximal anchoring of the endoloop with clips. (C) Closure of the endoloop with formation of the fundoplication.
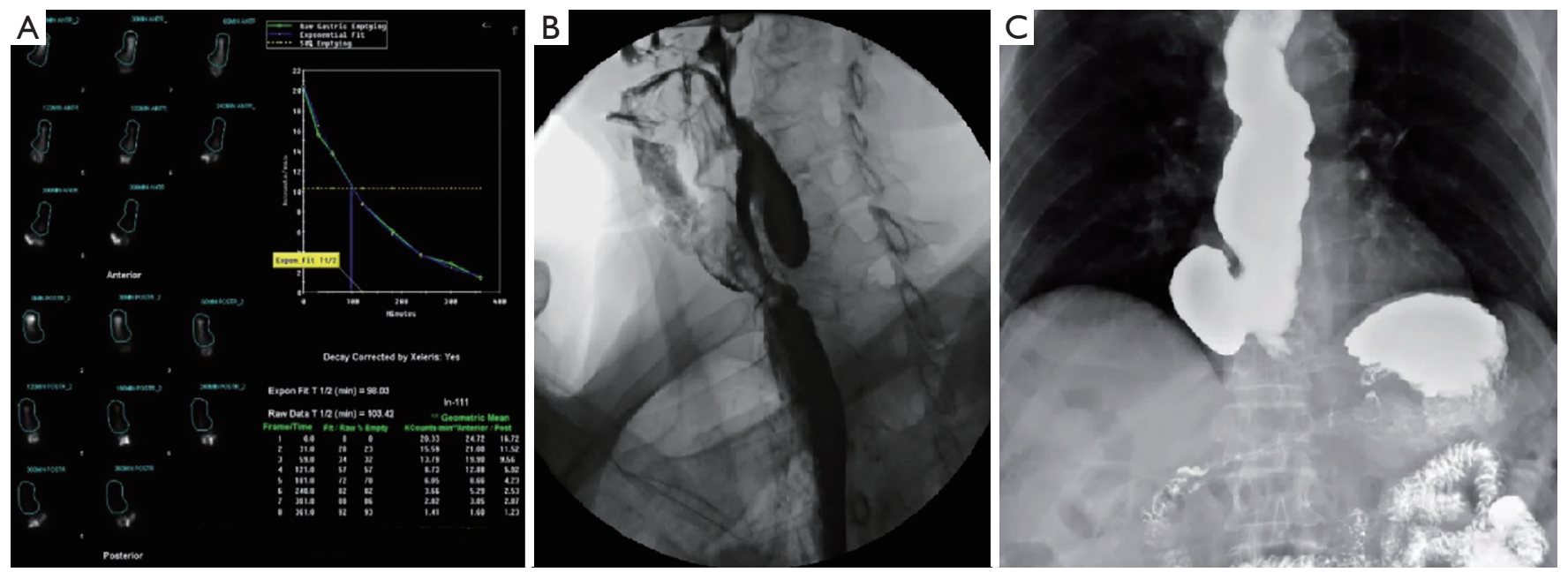

Figure 6 Applications of principles of endoscopic myotomy in other foregut disorders. (A) Typical gastric emptying study in the patient with refractory gastroparesis. Delay in emptying and retention of the radiolabeled meal is demonstrated. (B) Zenker's diverticulum. (C) Epiphrenic diverticulum.

procedure has expanded to treat other spastic esophageal motility disorders such as distal esophageal spasm (DES), hypercontractile and hypertensive esophageal peristalsis (jackhammer and nutcracker esophagus) (27,40-48). In 2015, Khashab et al. retrospectively reported on the efficacy and safety of POEM for the treatment of patients with spastic esophageal disorders (SEDs) (46). A total of 73 patients from multiple centers were reviewed, including 9 patients with DES, 10 with jackhammer esophagus, and 54 with spastic achalasia. Clinical success was observed in $93 \%$ of patients with overall decrease in Eckardt scores from
6.73 to 1.13 after an average follow up of eight months. Resolution of initial abnormal manometric parameters were observed in all 73 patients with $11 \%$ experiencing a mild adverse event.

The success of POEM gave rise to similar procedures for the treatment of other conditions. Procedure equivalent to the surgical pyloromyotomy, termed gastric peroral endoscopic myotomy (G-POEM), also known as peroral pyloromyotomy (POP) is developed for the treatment of refractory gastroparesis (Figure 6A) $(45,47,49)$. For G-POEM procedure a submucosal tunnel is typically 
created $5 \mathrm{~cm}$ proximal to the pylorus along the greater curvature or anterior gastric wall and a pyloromyotomy with short antral myotomy is performed. Several publications have shown G-POEM be a safe and effective treatment modality for refractory gastroparesis (47,48,50-52). In 2017, Khashab et al. reported on their multicenter experience with G-POEM in 30 patients with refractory gastroparesis (11 diabetic, 12 postsurgical, 7 idiopathic) (51). A G-POEM was successfully completed in all patients with adverse events occurring in $6.7 \%$, comprising of one pneumoperitoneum and one pre-pyloric ulcer. A clinical response, defined as improvement in gastroparetic symptoms with absence of recurrent hospitalization, was observed in $26(86 \%)$ of patients during a median follow up time of 5.5 months. Repeat gastric emptying studies were obtained in 17 patients and normalized in 8 patients (47\%) and improved in 6 patients (35\%). Authors concluded that the G-POEM is technically feasible and an effective treatment for patients with gastroparesis refractory to medical therapy and leads to normalization or improvement of GES in the majority of treated patients.

Similarly, POEM principles were applied for the treatment of the esophageal diverticula, termed D-POEM or POD procedure (Figure 6B,C) (53-55). In the analysis of 25 patients with Zenker's or epiphrenic diverticula D-POEM procedure had $100 \%$ technical success rate with $86 \%$ clinical success rate and no long term adverse events (52). In another multicenter international study on the effectiveness of the D-POEM in the management of the Zenker's diverticula authors observed technical success rate of $97.3 \%$ and clinical success rate of $92 \%$ with low rate of adverse events (6.7\%), proving yet another safety and feasibility of this promising technology in the clinical practice (55).

\section{Authors experience}

Authors have performed in total 80 endoscopic submucosal myotomy procedures. There were 37 (46\%) POEM, 40 (50\%) GPOEM, 2 (3\%) submucosal tunneling endoscopic resection (STER) procedures for resection of the esophageal leiomyoma and 1 (1\%) DPOEM procedure. Average follow up in our series is 22 months.

Among 37 patients with POEM procedures, there was $15(41 \%)$ males and $22(59 \%)$ females. Mean age was $61 \pm 12$ years. POEM procedure was performed for achalasia in $32(86 \%)$ and jackhammer esophagus in $5(14 \%)$ cases. There were $22(69 \%)$ patients with type I or II and 10 (31\%) with type III achalasia. Three (9\%) patients had end stage achalasia with sigmoid esophagus. Two (6\%) patients had prior surgical myotomy and all had at least one previous intervention with Botox injection, endoscopic or pneumatic dilation. Standard procedure included posterior transverse mucosotomy and tunneling, posterior myotomy and closure of the mucosal defect with OverStitch device (Apollo Endosurgery, Inc, Austin, TX, USA). Length of the myotomy was defined by the manometry findings. Average length for type I or II achalasia was $8 \pm 2 \mathrm{~cm}$. For type III achalasia average length of the myotomy was $21 \pm 2 \mathrm{~cm}$. For Nutcracker esophagus myotomy was performed to the LES without its division. Average length of the myotomy was $18 \pm 2 \mathrm{~cm}$. Technical success rate was $100 \%$ and clinical success, based on the symptom resolution and Eckardt was $97 \%$. One (3\%) patient required re-do posterior POEM procedure six months after failed anterior procedure, leading to complete resolution of symptoms. Thirty (81\%) patients had evidence of free air on the postoperative CXR and $4(11 \%)$ required decompression of tension pneumoperitoneum via laparocentesis with the Veress needle. Incidence of pneumoperitoneum has decreased after switching from high or medium to low insufflation for the tunnel dissection. Two (6\%) patients required stent placement intraoperatively due to failure of the mucosal closure with either OverStitch or clips. As the result of technical difficulties with endoscopic suturing, clips were used for rescue closure in $11(30 \%)$ patients. Use of clips has decreased with learning curve-whereas in first 20 patients clips were used $8(40 \%)$ times, in the later 17 cases it was required only $3(18 \%)$ times. 33 (89\%) patients were discharged on POD 1. Four (11\%) patients had longer hospital stay due to complications. Postoperatively 11 (30\%) patients are taking PPIs for GERD.

Among 40 patients, undergoing GPOEM procedure, there were $8(20 \%)$ males and $32(80 \%)$ females. Mean age was $48 \pm 14$ years. Etiology included idiopathic (19, $48 \%)$ or diabetic $(19,48 \%)$ gastroparesis and postsurgical (conduit obstruction) after esophagectomy in $2(5 \%)$. Technique consisted of the transverse mucosotomy and pyloromyotomy on the greater curvature to the subserosal layer with closure of the mucosotomy with endoscopic suturing. 11 (28\%) patients had full thickness myotomy through the serosal layer without consequences. Interestingly, free air was observed at significantly lower rate $11(28 \%)$, and was not always seen even after confirmed peritoneal entry. One (3\%) patient developed postoperative bleeding requiring transfusion of four units of blood and one patient returned to OR on POD 2 for diagnostic laparoscopy 
Table 1 Type and incidence of adverse events in authors' series of submucosal endoscopic myotomy cases

\begin{tabular}{llcc}
\hline Procedure & Complication & N & $\%$ \\
\hline POEM & Free air & 30 & $81 \%$ \\
& Tension pneumoperitoneum & 4 & $11 \%$ \\
& Pneumothorax & 1 & $3 \%$ \\
& Rescue clips & 11 & $30 \%$ \\
& Stent placement. & 2 & $6 \%$ \\
GPOEM & Lack of improvement & 1 & $3 \%$ \\
& Free air & 11 & $28 \%$ \\
& Full thickness myotomy & 11 & $28 \%$ \\
& Bleeding requiring transfusion & 1 & $3 \%$ \\
& Return to OR for suspected leak & 1 & $3 \%$ \\
& Rescue clips & 8 & $20 \%$ \\
& Lack of improvement & 10 & $25 \%$ \\
& Stent placement & 2 & $100 \%$ \\
\hline
\end{tabular}

due to abdominal pain and suspected leak, that was ruled out. Rescue clips were used in 8 (20\%) patients. Technical success rate was $100 \%$ and clinical-75\%. 37 (93\%) patients were discharged on POD 1. Three patients required longer hospital stay (Table 1).

Two patients (both females, 38 and 57 years) underwent esophageal leiomyoma resection via STER. In both cases there were failure of mucosotomy closure, requiring stent placement. Both were managed endoscopically without surgical interventions. Other than prolonged hospital-stay (14 and 4 days), these patients had no negative long-term consequences.

One patient, 84 years old female, underwent successful DPOEM procedure for the epiphrenic diverticulum without complications.

In authors experience POEM and other endoscopic submucosal myotomy procedures are safe options for management of wide spectrum of benign foregut motility problems.

\section{Conclusion}

Peroral endoscopic myotomy is a new technology in the management of patients with achalasia. It is applicable to all types of the achalasia as well as other, non-achalasia spastic esophageal motility disorders. It has proven to be safe, effective, and feasible minimally invasive endoscopic treatment option and has some advantages over traditional surgical intervention. Its principles can be applied for management of other conditions with similar goal and objective of the myotomy as has been demonstrated in gastroparesis and esophageal diverticula patients.

\section{Acknowledgments}

Funding: This research was funded in part through the NIH/NCI Cancer Center Support Grant P30 CA006927.

\section{Footnote}

Provenance and Peer Review: This article was commissioned by the Guest Editor (Abbas, Ghulam) and the editorial office for the series "Minimally Invasive Esophageal Surgery", published in Shanghai Chest. This article has undergone external peer review.

Conflicts of Interest: All authors have completed the ICMJE uniform disclosure form (available at http://dx.doi. org/10.21037/shc.2020.02.02). The series "Minimally Invasive Esophageal Surgery" was commissioned by the editorial office without any funding or sponsorship. The authors have no other conflicts of interest to declare.

Ethical Statement: The authors are accountable for all aspects of the work in ensuring that questions related to the accuracy or integrity of any part of the work are appropriately investigated and resolved.

Open Access Statement: This is an Open Access article distributed in accordance with the Creative Commons Attribution-NonCommercial-NoDerivs 4.0 International License (CC BY-NC-ND 4.0), which permits the noncommercial replication and distribution of the article with the strict proviso that no changes or edits are made and the original work is properly cited (including links to both the formal publication through the relevant DOI and the license). See: https://creativecommons.org/licenses/by-nc-nd/4.0/.

\section{References}

1. Inoue H, Minami H, Kobayashi $\mathrm{Y}$, et al. Peroral endoscopic myotomy (POEM) for esophageal achalasia. Endoscopy 2010;42:265-71. 
2. Swanstrom LL, Kurian A, Dunst CM, et al. Long-term outcomes of an endoscopic myotomy for achalasia: the POEM procedure. Ann Surg 2012;256:659-67.

3. Kahrilas PJ, Katzka D, Richter JE. Clinical Practice Update: The Use of Per-Oral Endoscopic Myotomy in Achalasia: Expert Review and Best Practice Advice From the AGA Institute. Gastroenterology 2017;153:1205-11.

4. Zaninotto G, Bennett C, Boeckxstaens G, et al. The 2018 ISDE achalasia guidelines. Dis Esophagus 2018;31. doi: 10.1093/dote/doy071.

5. Kane ED, Budhraja V, Desilets DJ, et al. Myotomy length informed by high-resolution esophageal manometry (HREM) results in improved per-oral endoscopic myotomy (POEM) outcomes for type III achalasia. Surg Endosc 2019;33:886-94.

6. Schaheen LW, Sanchez MV, Luketich JD. Peroral Endoscopic Myotomy for Achalasia. Thorac Surg Clin 2018;28:499-506.

7. Tyberg A, Sharaiha RZ, Familiari P, et al. Peroral endoscopic myotomy as salvation technique post-Heller: International experience. Dig Endosc 2018;30:52-6.

8. Ngamruengphong S, Inoue H, Ujiki MB, et al. Efficacy and Safety of Peroral Endoscopic Myotomy for Treatment of Achalasia After Failed Heller Myotomy. Clin Gastroenterol Hepatol 2017;15:1531-1537.e3.

9. Vigneswaran Y, Yetasook AK, Zhao JC, et al. Peroral endoscopic myotomy (POEM): feasible as reoperation following Heller myotomy. J Gastrointest Surg 2014;18:1071-6.

10. Schneider AM, Louie BE, Warren HF, et al. Matched Comparison of Per Oral Endoscopic Myotomy to Laparoscopic Heller Myotomy in the Treatment of Achalasia. J Gastrointest Surg 2016;20:1789-96.

11. Schuchert MJ, Luketich JD, Landreneau RJ, et al. Minimally invasive surgical treatment of sigmoidal esophagus in achalasia. J Gastrointest Surg 2009;13:102935; discussion 1035-6.

12. Hu JW, Li QL, Zhou PH, et al. Peroral endoscopic myotomy for advanced achalasia with sigmoid-shaped esophagus: long-term outcomes from a prospective, singlecenter study. Surg Endosc 2015;29:2841-50.

13. Haito-Chavez Y, Inoue H, Beard KW, et al. Comprehensive Analysis of Adverse Events Associated With Per Oral Endoscopic Myotomy in 1826 Patients: An International Multicenter Study. Am J Gastroenterol 2017;112:1267-76.

14. Petrov R, Bakhos C, Abbas A. Robotic Esophagectomy. In: Tsuda S, Kudsi OY, editors. Robotic-Assisted Minimally Invasive
Surgery. Switzerland: Springer Nature.; 2019. p. 277-93.

15. Inoue, $\mathrm{H}, \mathrm{Minami}, \mathrm{H}$, Satodate, $\mathrm{H}$ et al. First clinical experience of submucosal endoscopic myotomy for esophageal achalasia with no skin incision. Gastrointest Endosc 2009;69:AB122.

16. Eleftheriadis $\mathrm{N}$, Inoue $\mathrm{H}$, Ikeda $\mathrm{H}$, et al. Training in peroral endoscopic myotomy (POEM) for esophageal achalasia. Ther Clin Risk Manag 2012;8:329-42.

17. Li QL, Chen WF, Zhou PH, et al. Peroral endoscopic myotomy for the treatment of achalasia: a clinical comparative study of endoscopic full-thickness and circular muscle myotomy. J Am Coll Surg 2013;217:442-51.

18. Teitelbaum EN, Soper NJ, Arafat FO, et al. Analysis of a learning curve and predictors of intraoperative difficulty for peroral esophageal myotomy (POEM). J Gastrointest Surg 2014;18:92-8; discussion 98-9.

19. Lv H, Zhao N, Zheng Z, et al. Analysis of the learning curve for peroral endoscopic myotomy for esophageal achalasia: Single-center, two-operator experience. Dig Endosc 2017;29:299-306.

20. Tan Y, Lv L, Wang X, et al. Efficacy of anterior versus posterior per-oral endoscopic myotomy for treating achalasia: a randomized, prospective study. Gastrointest Endosc 2018;88:46-54.

21. Tyberg A, Seewald S, Sharaiha RZ, et al. A multicenter international registry of redo per-oral endoscopic myotomy (POEM) after failed POEM. Gastrointest Endosc 2017;85:1208-11.

22. Von Renteln D, Fuchs KH, Fockens P, et al. Peroral endoscopic myotomy for the treatment of achalasia: an international prospective multicenter study.

Gastroenterology 2013;145:309-11.e1-3.

23. Familiari P, Gigante G, Marchese M, et al. Peroral Endoscopic Myotomy for Esophageal Achalasia: Outcomes of the First 100 Patients With Short-term Follow-up. Ann Surg 2016;263:82-7.

24. Werner YB, Costamagna G, Swanstrom LL, et al. Clinical response to peroral endoscopic myotomy in patients with idiopathic achalasia at a minimum follow-up of 2 years. Gut 2016;65:899-906.

25. Schlottmann F, Luckett DJ, Fine J, et al. Laparoscopic Heller Myotomy Versus Peroral Endoscopic Myotomy (POEM) for Achalasia: A Systematic Review and Metaanalysis. Ann Surg 2018;267:451-60.

26. Meng F, Li P, Wang Y, et al. Peroral endoscopic myotomy compared with pneumatic dilation for newly diagnosed achalasia. Surg Endosc 2017;31:4665-72.

27. Kumbhari V, Tieu AH, Onimaru M, et al. Peroral 
endoscopic myotomy (POEM) vs laparoscopic Heller myotomy (LHM) for the treatment of Type III achalasia in 75 patients: a multicenter comparative study. Endosc Int Open 2015;3:E195-201.

28. Fernandez-Ananin S, Fernandez AF, Balague C, et al. What to do when Heller's myotomy fails? Pneumatic dilatation, laparoscopic remyotomy or peroral endoscopic myotomy: A systematic review. J Minim Access Surg 2018;14:177-84.

29. Kumbhari V, Familiari P, Bjerregaard NC, et al. Gastroesophageal reflux after peroral endoscopic myotomy: a multicenter case-control study. Endoscopy 2017;49:634-42.

30. Johansson J, Hakansson HO, Mellblom L, et al. Prevalence of precancerous and other metaplasia in the distal oesophagus and gastro-oesophageal junction. Scand J Gastroenterol 2005;40:893-902.

31. Hvid-Jensen F, Pedersen L, Drewes AM, et al. Incidence of adenocarcinoma among patients with Barrett's esophagus. N Engl J Med 2011;365:1375-83.

32. Freedberg DE, Kim LS, Yang YX. The Risks and Benefits of Long-term Use of Proton Pump Inhibitors: Expert Review and Best Practice Advice From the American Gastroenterological Association. Gastroenterology 2017;152:706-15.

33. Cheung KS, Chan EW, Wong AYS, et al. Long-term proton pump inhibitors and risk of gastric cancer development after treatment for Helicobacter pylori: a population-based study. Gut 2018;67:28-35.

34. Bakhos CT, Petrov RV, Parkman HP, et al. Role and safety of fundoplication in esophageal disease and dysmotility syndromes. J Thorac Dis 2019;11:S1610-7.

35. Inoue H, Shiwaku H, Kobayashi Y, et al. Statement for gastroesophageal reflux disease after peroral endoscopic myotomy from an international multicenter experience. Esophagus 2020;17:3-10.

36. Trad KS, Fox MA, Simoni G, et al. Transoral fundoplication offers durable symptom control for chronic GERD: 3-year report from the TEMPO randomized trial with a crossover arm. Surg Endosc 2017;31:2498-508.

37. Hunter JG, Kahrilas PJ, Bell RC, et al. Efficacy of transoral fundoplication vs omeprazole for treatment of regurgitation in a randomized controlled trial. Gastroenterology 2015;148:324-333.e5.

38. Brewer Gutierrez OI, Benias PC, Khashab MA. SameSession Per-Oral Endoscopic Myotomy Followed by Transoral Incisionless Fundoplication in Achalasia: Are We There Yet? Am J Gastroenterol 2020;115:162.

39. Inoue H, Ueno A, Shimamura Y, et al. Peroral endoscopic myotomy and fundoplication: a novel NOTES procedure. Endoscopy 2019;51:161-4.

40. Minami $\mathrm{H}$, Isomoto $\mathrm{H}$, Yamaguchi $\mathrm{N}$, et al. Peroral endoscopic myotomy (POEM) for diffuse esophageal spasm. Endoscopy 2014;46 Suppl 1 UCTN:E79-81.

41. Shiwaku H, Inoue H, Beppu R, et al. Successful treatment of diffuse esophageal spasm by peroral endoscopic myotomy. Gastrointest Endosc 2013;77:149-50.

42. Sharata AM, Dunst CM, Pescarus R, et al. Peroral endoscopic myotomy (POEM) for esophageal primary motility disorders: analysis of 100 consecutive patients. J Gastrointest Surg 2015;19:161-70; discussion 170.

43. Ko WJ, Lee BM, Park WY, et al. Jackhammer esophagus treated by a peroral endoscopic myotomy. Korean J Gastroenterol 2014;64:370-4.

44. Takahashi K, Sato H, Sato Y, et al. Education and Imaging. Gastroenterology: Histopathological investigation of distal esophageal spasm (DES) using per-oral endoscopic myotomy (POEM). J Gastroenterol Hepatol 2015;30:1113.

45. Khashab MA, Stein E, Clarke JO, et al. Gastric peroral endoscopic myotomy for refractory gastroparesis: first human endoscopic pyloromyotomy (with video). Gastrointest Endosc 2013;78:764-8.

46. Khashab MA, Messallam AA, Onimaru M, et al. International multicenter experience with peroral endoscopic myotomy for the treatment of spastic esophageal disorders refractory to medical therapy (with video). Gastrointest Endosc 2015;81:1170-7.

47. Gonzalez JM, Vanbiervliet G, Vitton V, et al. First European human gastric peroral endoscopic myotomy, for treatment of refractory gastroparesis. Endoscopy 2015;47 Suppl 1 UCTN:E135-6.

48. Zoll B, Jehangir A, Edwards MA, et al. Surgical Treatment for Refractory Gastroparesis: Stimulator, Pyloric Surgery, or Both? J Gastrointest Surg 2020;24:2204-11.

49. Malik Z, Kataria R, Modayil R, et al. Gastric Per Oral Endoscopic Myotomy (G-POEM) for the Treatment of Refractory Gastroparesis: Early Experience. Dig Dis Sci 2018;63:2405-12.

50. Jung Y, Lee J, Gromski MA, et al. Assessment of the length of myotomy in peroral endoscopic pyloromyotomy (G-POEM) using a submucosal tunnel technique (video). Surg Endosc 2015;29:2377-84.

51. Khashab MA, Ngamruengphong S, Carr-Locke D, et al. Gastric per-oral endoscopic myotomy for refractory gastroparesis: results from the first multicenter study on endoscopic pyloromyotomy (with video). Gastrointest Endosc 2017;85:123-8. 
52. Bapaye A, Dubale N, Pujari R, et al. Peroral endoscopic pyloromyotomy for delayed postoperative gastroparesis. Endoscopy 2015;47:E581-2.

53. Maydeo A, Patil GK, Dalal A. Operative technical tricks and 12-month outcomes of diverticular peroral endoscopic myotomy (D-POEM) in patients with symptomatic esophageal diverticula. Endoscopy 2019;51:1136-40.

54. Orlandini B, Barret M, Guillaumot MA, et al. Per-oral

doi: $10.21037 /$ shc.2020.02.02

Cite this article as: Petrov RV, Fajardo RA, Bakhos CT, Abbas AE. Peroral endoscopic myotomy: techniques and outcomes. Shanghai Chest 2021;5:14. endoscopic myotomy for esophageal diverticula with or without esophageal motility disorders. Clin Res Hepatol Gastroenterol 2020;44:82-9.

55. Yang J, Zeng X, Yuan X, et al. An international study on the use of peroral endoscopic myotomy (POEM) in the management of esophageal diverticula: the first multicenter D-POEM experience. Endoscopy 2019;51:346-9. 